\title{
Treatment of Lupus Nephritis by Mycophenolate Mofetil
}

\author{
Violeta Rabrenovića Mileta Poskuricab Zoran Kovačevića Vidosava Nešićc \\ Marina Savin c Branka Mitićd Nada Dimkoviće Čedomir Čučkoviće \\ Danica Vujiće Steva Plješa ${ }^{f}$ Gordana Peruničić-Pekovićf ${ }^{\text {Slobodan Čurićg }}$ \\ Igor Mitićg Marina Ratković ${ }^{h}$ Jelena Marinkovići Dragan Jovanovića \\ Clinics of Nephrology, ${ }^{a}$ Military Medical Academy, ${ }^{b}$ Kragujevac Clinical Center, ${ }^{c}$ Clinical Center of Serbia,

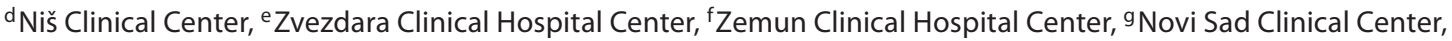 \\ ${ }^{\mathrm{h}}$ Clinical Center of Montenegro, and 'Institute of Social Medicine, Statistics and Health Research, School of \\ Medicine, University of Belgrade, Belgrade, Serbia
}

\section{Key Words}

Lupus nephritis $\cdot$ Mycophenolate mofetil $\cdot$ Maintenance therapy

\begin{abstract}
Background/Aims: Mycophenolate mofetil (MMF) has been increasingly used for the treatment of lupus nephritis (LN). The aim of this study was to examine the efficacy and safety of MMF used with low doses of corticosteroids as maintenance therapy in patients with LN. Methods: The study covered 35 patients, most of them with proliferative types of $L N$ ( 5 WHO class III, 26 class IV), while 1 had class V and 3 class VI nephritis. MMF was administered in the dose of $1.5-2 \mathrm{~g} / 24 \mathrm{~h}$ and prednisone at $10-20 \mathrm{mg} /$ day. The treatment effects were followed over a 12-month period. Results: After 3 months of therapy significant reduction in proteinuria was achieved $(2.1 \pm 2.4 \mathrm{~g} / 24 \mathrm{~h}$ vs. $1.0 \pm 1.0 \mathrm{~g} / 24 \mathrm{~h}, \mathrm{p}<0.01)$ and maintained to the end of the study. In parallel, a significant rise in serum albumin, a fall of cholesterol and a significant increase in mean glomerular filtration rate were noted. Complete remission was achieved in 16 patients $(45.7 \%)$, includ-
\end{abstract}

ing all patients in class III and V plus 10 patients in class IV. Not a single adverse effect was observed. Conclusion: MMF combined with low doses of steroids is an effective and safe treatment for the maintenance of stable remission of $L N$.

Copyright $\odot 2010$ S. Karger AG, Basel

\section{Introduction}

Lupus nephritis (LN) is a common manifestation of systemic lupus erythematosus (SLE) and a significant prognostic factor of the disease [1]. In recent decades early detection of kidney disease in SLE patients and aggressive immunosuppression therapy have led to improved patient and kidney survival. High-dose corticosteroids and cyclophosphamide are widely used as an effective regimen that enables a high rate of disease remission and preserves kidney function [2-5]. However, the use of this regimen is limited by potentially serious adverse effects that motivate the search for effective alternative immunosuppressive agents.

\section{KARGER \\ Fax +41613061234 E-Mail karger@karger.ch} www.karger.com

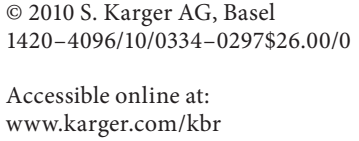

Prim. Dr. Violeta Rabrenović

Clinic of Nephrology, Military Medical Academy

Crnotravska bb

RS-11000 Belgrade (Serbia)

Tel. +381 641398 436, E-Mail violetarabrenovic@yahoo.com 
Mycophenolate mofetil (MMF) effectively and selectively suppresses $\mathrm{T}$ and $\mathrm{B}$ lymphocyte proliferation, antibody production and expression of proinflammatory adhesion molecules on lymphocytes [6]. It was initially administered to prevent acute rejection of renal allografts [7] but is currently also applied in the treatment of primary glomerulonephritis and LN [8-13]. MMF has been used for induction and maintenance treatment, especially in patients with severe $\mathrm{LN}$, those with LN refractory to cyclophosphamide and subjects who cannot tolerate cyclophosphamide.

In the present study, MMF was administered to LN patients in whom only partial remission had been achieved by previous therapy with cyclophosphamide and corticosteroids but the maintenance therapy with these drugs had become inconvenient due to the occurrence of adverse effects or the need to employ high doses of steroids. The aim of the investigation was to examine the efficacy and safety of MMF given with low doses of corticosteroids as maintenance therapy to patients with LN.

\section{Patients and Methods}

The multicenter prospective 12-month study comprised $35 \mathrm{pa}-$ tients. All had evidenced SLE according to American College of Rheumatology diagnostic criteria [14] and LN with pathohistological verification of the lesion according to the WHO classification [15]. In addition, the activity index and chronicity index for proliferative types of LN were evaluated [16].

Previous immunosuppressive treatment was initiated with pulse doses of 250-500 mg of methylprednisolone adjusted to the body weight (3 pulse doses), with pulse doses of cyclophosphamide adjusted to creatinine clearance up to $1,000 \mathrm{mg} / \mathrm{m}^{2}$. After the steroid pulses, oral prednisolone was continued at $0.5 \mathrm{mg} / \mathrm{kg}$ body weight. The cyclophosphamide therapy was continued once a month over a 6-month period. Partial remission ensued in all 35 patients, but in many of them proteinuria remained above $2 \mathrm{~g} /$ day with concomitant occurrence of adverse effects to both cyclophosphamide and steroids, or the necessary administration of high doses of steroids. Accordingly MMF treatment was initiated together with low doses of steroids.

The ethics committee of the Clinical Center of Serbia evaluated and approved this study, and all patients gave their informed consent.

MMF was applied in a dose of $1.5 \mathrm{~g} / 24 \mathrm{~h}$ in patients with renal failure and at $2 \mathrm{~g} / 24 \mathrm{~h}$ in patients without renal failure, while prednisolone was administered in doses of $10-20 \mathrm{mg} / \mathrm{day}$. Other immunosuppressants were not used. All patients received angiotensin-converting enzyme inhibitors, which had been started prior to the present study. The treatment effects were followed up at 3 -month intervals when the patients were subjected to detailed physical examinations including measurement of blood pressure (BP). The mean arterial pressure was calculated using the follow-
Table 1. Baseline characteristics of patients

$\begin{array}{lc}\text { Female gender } & 31(89) \\ \text { Age, years } & 36.8 \pm 11.8 \\ \text { Systolic BP, mm Hg } & 131.9 \pm 15.0 \\ \text { Diastolic BP, mm Hg } & 84.1 \pm 9.8 \\ \text { WHO class III } & 5(14) \\ \text { WHO class IV } & 26(74) \\ \text { WHO class V } & 1(3) \\ \text { WHO class VI } & 3(9)\end{array}$

Figures are means $\pm \mathrm{SD}$ or numbers of cases with percentages in parentheses.

ing equation: [systolic $\mathrm{BP}+2($ diastolic $\mathrm{BP})] / 3$. In addition, serum creatinine, albumin, cholesterol, triglycerides, anti-doublestranded DNA antibodies and complement were determined, together with 24-hour proteinuria and urine sediment. Glomerular filtration rate (GFR) was calculated by the mean GFR formula [17].

Complete remission of the disease was defined as proteinuria $<0.3 \mathrm{~g} / 24 \mathrm{~h}$ with normal urinary sediment, normal serum albu$\min (\geq 35 \mathrm{~g} / \mathrm{l})$ and creatinine levels and creatinine clearance $\leq 15 \%$ above the baseline values. Partial remission was defined as proteinuria between 0.3 and $2.9 \mathrm{~g} / 24 \mathrm{~h}$ with a serum albumin level of at least $30.0 \mathrm{~g} / \mathrm{l}$ and stable renal function. Adverse effects of the drugs were regularly monitored as well.

The results are presented as means $\pm \mathrm{SD}$. Comparison of the studied parameters over the follow-up period was accomplished by 1-way ANOVA with repeated measurements. Comparisons in different time intervals and between different subgroups were conducted by the test (with corrections according to Bonferroni).

\section{Results}

Table 1 illustrates baseline patient information and their distribution into pathomorphological classes according to the WHO classification. Most patients suffered from proliferative LN types, while only 1 had WHO class V and 3 had WHO class VI nephritis. The mean activity index score for proliferative LN types (types III and IV) was $8.6 \pm 3.3$ and the chronicity index score was 2.0 \pm 1.1 .

The results of baseline laboratory tests and values over 12 months of treatment are presented in table 2. Proteinuria was significantly reduced already after 3 months, and significantly less proteinuria was recorded at all follow-up points in comparison with the baseline values. At the same time, a significant rise in serum albumin concentration was noted, as well as a fall of cholesterol level. 
Table 2. Laboratory and BP values at the outset of the study (baseline) and during the follow-up

\begin{tabular}{|c|c|c|c|c|c|c|}
\hline & 0 months & 3 months & 6 months & 9 months & 12 months & $\mathrm{p}$ \\
\hline GFR (MDRD), $\mathrm{ml} / \mathrm{min} / 1.73 \mathrm{~m}^{2}$ & $63.8 \pm 23.1$ & $74.3 \pm 27.7$ & $72.2 \pm 23.1$ & $78.3 \pm 25.0$ & $74.1 \pm 24.2$ & 0.001 \\
\hline S-creatinine, $\mu \mathrm{mol} / \mathrm{l}$ & $119 \pm 75$ & $99 \pm 50$ & $99 \pm 48$ & $96 \pm 39$ & $102 \pm 76$ & 0.035 \\
\hline S-albumin, $\mathrm{g} / \mathrm{l}$ & $35.5 \pm 8.4$ & $36.7 \pm 6.5$ & $38.6 \pm 6.5$ & $38.7 \pm 7.1$ & $39.2 \pm 7.2$ & 0.002 \\
\hline S-cholesterol, mmol/l & $6.7 \pm 1.8$ & $6.3 \pm 1.6$ & $6.2 \pm 1.2$ & $6.0 \pm 1.3$ & $6.1 \pm 1.4$ & 0.023 \\
\hline Triglyceride, mmol/l & $2.2 \pm 0.8$ & $2.0 \pm 0.9$ & $1.8 \pm 0.7$ & $2.0 \pm 0.9$ & $2.1 \pm 1.4$ & 0.074 \\
\hline Serum C3, mg/dl & $0.83 \pm 0.66$ & $0.85 \pm 0.25$ & $0.82 \pm 0.31$ & $0.87 \pm 0.26$ & $0.95 \pm 0.27$ & 0.809 \\
\hline Serum C4, mg/dl & $0.21 \pm 0.16$ & $0.25 \pm 0.20$ & $0.25 \pm 0.23$ & $0.32 \pm 0.25$ & $0.28 \pm 0.21$ & 0.299 \\
\hline Urinary protein, $\mathrm{g} / 24 \mathrm{~h}$ & $2.1 \pm 2.4$ & $1.0 \pm 1.0$ & $0.8 \pm 0.9$ & $1.1 \pm 1.3$ & $1.1 \pm 1.5$ & 0.001 \\
\hline S-dsDNA, IU/ml & $63.8 \pm 71.3$ & n.a. & n.a. & n.a. & $81.2 \pm 85.3$ & 0.9956 \\
\hline $\mathrm{MAP}, \mathrm{mm} \mathrm{Hg}$ & $99.2 \pm 13.2$ & $97.8 \pm 11.2$ & $97.2 \pm 13.2$ & $100.8 \pm 12.0$ & $98.4 \pm 12.8$ & 0.2367 \\
\hline
\end{tabular}

Figures are means \pm SD. $p$ values: ANOVA. MDRD = Modification of Diet in Renal Disease; $S=$ serum; dsDNA $=$ anti-doublestranded DNA antibody; n.a. = not available.

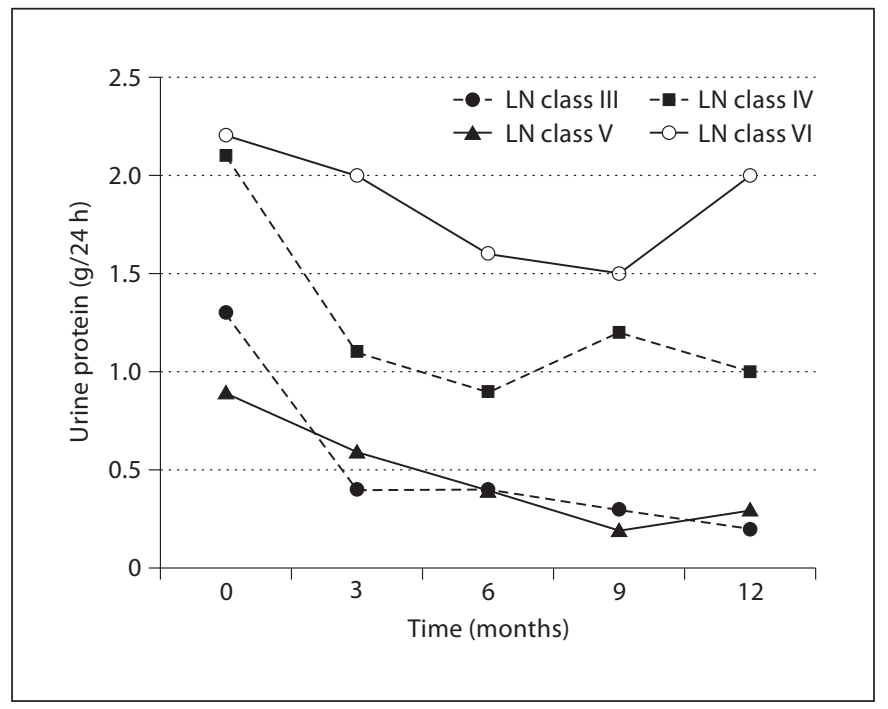

Fig. 1. Urine protein excretion in patients with different classes of LN during treatment with MMF.

A significant increase in the mean GFR was observed at all follow-ups in comparison with the baseline values. The mean value for serum creatinine declined over 9 months of treatment but then leveled out. The slight increase recorded at 12 months was not statistically significant ( $\mathrm{p}=0.6791$ for the difference between serum creatinine levels at 12 and 9 months). This tendency of the mean serum creatinine value appeared due to a large increase in serum creatinine in the patient with class V LN, who underwent an orthopedic intervention shortly be-

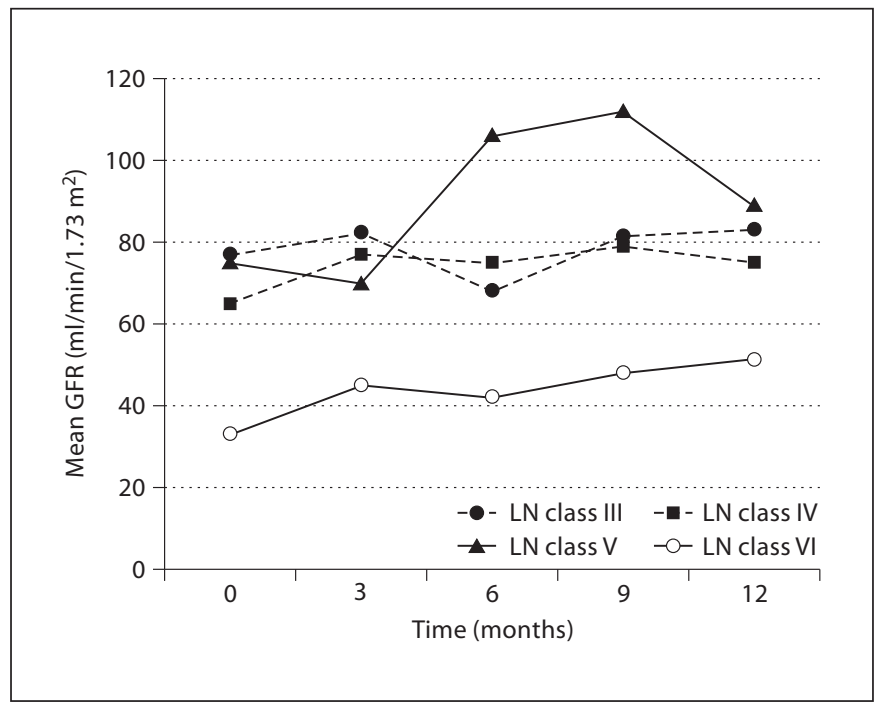

Fig. 2. GFR estimated by MDRD GFR equation in patients with different WHO classes of LN during treatment with MMF and low doses of prednisolone.

fore the last control. All patients were given angiotensinconverting enzyme inhibitors throughout the study period and the $\mathrm{BP}$ was maintained near the target level of 130/80 mm Hg (table 2).

After 12 months, 16 (45.7\%) out of 35 patients met the criteria for complete remission. Among them were all class III patients, 10/26 class IV patients and the single class $\mathrm{V}$ patient. Changes in mean proteinuria for patients in different LN classes over time are shown in figure 1. The highest values were maintained in class VI patients 
Table 3. Frequency of urine abnormalities at the outset and at the end of the study

\begin{tabular}{|c|c|c|c|c|c|c|}
\hline & \multicolumn{3}{|c|}{0 months } & \multicolumn{3}{|c|}{12 months } \\
\hline & $\begin{array}{l}\text { WHO } \\
\text { class III } \\
(\mathrm{n}=5)\end{array}$ & $\begin{array}{l}\text { WHO } \\
\text { class IV } \\
(\mathrm{n}=26)\end{array}$ & $\begin{array}{l}\text { WHO } \\
\text { class VI } \\
(\mathrm{n}=3)\end{array}$ & $\begin{array}{l}\text { WHO } \\
\text { class III }\end{array}$ & $\begin{array}{l}\text { WHO } \\
\text { class IV }\end{array}$ & $\begin{array}{l}\text { WHO } \\
\text { class VI }\end{array}$ \\
\hline \multicolumn{7}{|l|}{ Urine protein } \\
\hline $0.3-2.9 \mathrm{~g} / 24 \mathrm{~h}$ & 5 & 26 & 3 & 0 & 16 & 3 \\
\hline$<0.3 \mathrm{~g} / 24 \mathrm{~h}$ & 0 & 0 & 0 & 3 & 10 & 0 \\
\hline \multicolumn{7}{|l|}{ Urinary sediment } \\
\hline $\mathrm{RBC}>5 / \mathrm{HPF}$ & 1 & 16 & 0 & 0 & 2 & 0 \\
\hline $\mathrm{WBC}>5 / \mathrm{HPF}$ & 1 & 12 & 1 & 0 & 5 & 0 \\
\hline Cellular casts & 1 & 10 & 1 & 0 & 0 & 0 \\
\hline
\end{tabular}

The number of patients is presented. $\mathrm{RBC}=$ Red blood cells; $\mathrm{WBC}=$ white blood cells; $\mathrm{HPF}=$ high-power field.
Table 4. Comparison of variables registered at the outset of the study in 18 patients who achieved complete remission during the MMF treatment (group A) and 16 in whom complete remission was not achieved (group B)

\begin{tabular}{lccc}
\hline & Group A & Group B & p \\
\hline Age, years & $41.3 \pm 9.0$ & $31.2 \pm 12.8$ & 0.119 \\
MAP, mm Hg & $97.2 \pm 12.5$ & $102.2 \pm 9.1$ & 0.295 \\
GFR (MDRD), ml/min/1.73 $\mathrm{m}^{2}$ & $67.8 \pm 23.3$ & $59.3 \pm 22.7$ & 0.578 \\
Cholesterol, mmol/l & $6.5 \pm 1.5$ & $7.1 \pm 2.1$ & 0.460 \\
HDL cholesterol, mmol/l & $1.3 \pm 0.4$ & $1.4 \pm 0.3$ & 0.406 \\
LDL cholesterol, mmol/l & $3.5 \pm 1.3$ & $3.8 \pm 2.3$ & 0.158 \\
Triglyceride, mmol/l & $2.3 \pm 0.8$ & $2.0 \pm 0.8$ & 0.730 \\
Urinary protein, g/24 h & $1.1 \pm 0.3$ & $2.6 \pm 0.4$ & 0.019
\end{tabular}

Figures are means $\pm \mathrm{SD}$. MDRD $=$ Modification of Diet in Renal Disease.

over the whole 12 months and none of these patients achieved complete remission (table 3). Nevertheless, during this period their proteinuria slightly decreased, the serum albumin level became normal and GFR increased from $33 \pm 9$ to $51 \pm 14$ ( $\mathrm{p}=0.1343$; fig. 2$)$. Ten out of 26 class IV patients achieved complete remission. The other 16 patients remained in partial remission but their proteinuria decreased markedly during the study period (2.1 \pm 2.4 vs. $1.0 \pm 1.3 ; \mathrm{p}=0.0451$ ), urinary sediment normalized in 20 of them (table 3 ), while serum albumin concentration and GFR slightly increased (fig. 2).

Comparison of patients in whom MMF treatment resulted in complete remission with those whose protein- uria was not reduced $<0.3 \mathrm{~g} / 24 \mathrm{~h}$ showed that the groups differed only for the baseline level of proteinuria. Thus, the group which achieved complete remission had significantly lower proteinuria than the group in which complete remission was not achieved (table 4).

Over the studied period these patients manifested no adverse effects of MMF. Leukopenia, thrombocytopenia or infections (cytomegalovirus infection, Herpes virus infection) were not recorded. No patient reported discomforts such as nausea or vomiting. The transaminase levels were not elevated. Moreover, the adverse effects of corticosteroids (acne, facies lunata) were reduced and almost completely withdrew after the prednisolone dose had been reduced.

\section{Discussion}

In this study, MMF and low-dose prednisolone treatment were given as maintenance therapy for $\mathrm{LN}$ in patients in whom partial remission had been achieved by pulse doses of cyclophosphamide and corticosteroids. Proteinuria showed a significant decrease already after 3 months of MMF treatment, while complete remission was later achieved in 16 out of 35 treated patients. Over 1 year of therapy no adverse effects of MFF were noted and, since the dose of prednisolone was reduced, adverse effects of steroids either subsided or disappeared completely.

Mycophenolic acid, produced after hydrolysis of MMF, is the active part of this immunosuppressant, which has been increasingly used for the treatment of systemic dis- 
eases over recent years. Its selective and reversible inhibition of lymphocyte inosine-monophosphate-dehydrogenase enables the reduction of purine synthesis, selective suppression of lymphocyte proliferation and suppression of glycolysis of adhesive molecules, which all make it a drug affecting the prognosis of systemic diseases $[6,18]$.

Evidence for the beneficial effect of MMF in the treatment of autoimmune diseases was obtained in experimental models 10 years ago $[19,20]$. In humans, it was initially used as an induction treatment and subsequently for maintenance therapy, particularly in patients with proliferative LN [21-24]. Recently it was shown that MMF is also beneficial in membranous LN [25-27]. Our group of 35 patients included various LN types, most of whom (i.e. 26 or $74 \%$ ) suffered from diffuse proliferative LN. Only 6 patients in our study had a mild form of LN: 5 in class III and 1 in class V. The patients were treated in 8 clinical centers where a modification of the NIH protocol was used as the induction therapy for LN as recommended in our country at the time of this study. As an alternative to the NIH protocol the so-called 'Euro-Lupus regimen' was proposed 20 years ago. It represents a combination of a short course of a low-dose intravenous cyclophosphamide regimen followed by a maintenance phase with azathioprine [28]. Recently, instead of azathioprine, MMF was introduced for maintenance therapy and several studies attempted to answer whether it is superior to azathioprine or not $[5,29]$. Our main study objective was to examine the efficacy and safety of MMF given with low doses of corticosteroids as maintenance therapy in patients with LN who had achieved only partial remission after induction therapy and in addition had developed adverse effects to cyclophosphamide and steroids. Our aim was to find out whether MMF, as a newer and more effective immunosuppressive agent, could be beneficial in such cases, and therefore the study was not designed to compare the efficacy of MMF and azathioprine, which may be considered as a shortcoming.

During the first 3 months of MMF use, proteinuria decreased in each patient, and complete remission was achieved in all those with milder LN (classes III and V) and in 10/26 patients with LN class IV. Three patients in class VI, an advanced stage of LN, were also involved, but induction therapy with pulses of cyclophosphamide had been given to them and had resulted in partial remission. At the end of the induction therapy active urinary sediment remained in 1 subject, 2 had proteinuria near 3.0 $\mathrm{g} / 24 \mathrm{~h}$ and in 1 of them the $\mathrm{C} 3$ concentration fell during the last month of induction therapy. In addition, other adverse effects of the previous therapy appeared in all of them. As induction therapy resulted in stabilization of kidney function and decrease in proteinuria, these 3 patients were included in the present study, although immunosuppressive therapy is considered inadvisable for LN class VI patients. The use of MMF in this small group of patients enabled the reduction in the prednisolone dose and maintained stable renal function over 12 months with even a small rise in GFR. There are no data on the use of MMF in patients with class VI LN, and our modest results suggest that MMF can be used in carefully selected patients with serious chronic changes and have a beneficial effect on disease progression.

Chan et al. [24] reported $81 \%$ remission after the use of MMF and corticosteroid treatment, but the percentage of complete remission in our patients was somewhat lower, i.e. $45.7 \%$. However, similar proportions of complete remission were reported by Kapitsinou et al. [30] and Sahin et al. [26] using MMF to treat small groups of patients with different LN classes, like our group. The subgroup in which complete remission was achieved had significantly lower baseline proteinuria than the subgroup in which only partail remission occurred. Patients who did not achieve complete remission to the induction therapy and maintained proteinuria near the nephrotic range also showed a poor response to MMF treatment. Due to the small number of patients involved in our study, the use of the Cox model for analysis of predictors of remission was ineligible. Another study involving a larger number of patients indicated more abundant proteinuria as a negative predictor of remission together with some other factors, i.e. a delay in the initiation of immunosuppressive therapy, increased baseline serum creatinine, pathological classification, low serum $\mathrm{C} 3$ and hypertriglyceridemia [31, 32].

In our patients no adverse effects were noted. Not a single case of infection was reported and monitoring of the differential count showed no significant changes in the average values for granulocytes, monocytes and lymphocytes. Also, the mean transaminase levels did not change when the baseline values were compared with the follow-up results. Although the optimum treatment for LN has not been established, several authors suggest similar efficacy of MMF and cyclophosphamide in the maintenance of $\mathrm{LN}$ remission, where MMF is tolerated better due to fewer adverse reactions [22-24, 26]. However, adverse effects of MMF, such as diarrhea, vomiting and infectious complications, have been reported [24, 26, 33, 34]. It has also been noted that MMF treatment in LN is related to much milder manifestations of undesirable effects than in transplanted patients, which is most prob- 
ably related to more intensive immunosuppression in transplanted patients. Chan et al. [24] reported a more common occurrence of infections in their group, but the course was not serious. Some authors suggest the need for monitoring serum medroxyprogesterone acetate (MPA) levels. Neumann et al. [35] measured MPA and MPAglucuronide concentrations by HPLC in patients with autoimmune diseases and patients with a transplanted kidney. The levels of MPA over $12 \mathrm{~h}$ were higher in the former than in the latter group. Interindividual differences in pharmacokinetics were also noted within the groups. That led to the conclusion that subsequent studies should be used for careful determination of the effective dose of the drug with monitoring of MMF levels in patients with autoimmune diseases, taking into account interindividual differences $[35,36]$.

The present study is unfortunately an uncontrolled observational one, but, like other similar uncontrolled observational studies [22, 32, 37, 38], it also confirmed that MMF treatment led to reduction in proteinuria in all patients and that complete remission was attained in almost one half, which could not be achieved with the pre- vious cyclophosphamide treatment. Moreover, no adverse effects were reported, which was a problem with the previous regime, and renal function remained stable. Another shortcoming of the study was the heterogeneity of our relatively small group, although most patients had class IV diffuse proliferative LN. The study included 5 patients in class III and 1 in class V with a more favorable prognosis and a better response to immunosuppressive treatment, but also 3 class VI patients. In spite of the heterogeneity of the whole group, the results substantiate the efficacy and safety of MMF treatment in all subgroups and may contribute to the development of the MMF treatment profile for $\mathrm{LN}$ patients.

\section{Conclusion}

Our experience suggests that MMF combined with low steroid doses is an effective treatment for the maintenance of stable remission of SLE with LN. Over 12 months of follow-up, this mode of treatment showed a very good safety profile.

\section{References}

-1 Fiehn C, Hajjar Y, Mueller K, Waldherr R, Ho AD, Andrassy K: Improved clinical outcome of lupus nephritis during the past decade: Importance of early diagnosis and treatment. Ann Rheum Dis 2003;62:435439.

-2 Steinberg AD, Steinberg SC: Long-term preservation of renal function in patients with lupus nephritis receiving treatment that includes cyclophosphamide versus those treated with prednisone only. Arthritis Rheum 1991;34:945-950.

>3 Boumpas DT, Austin HA 3rd, Vaughn EM, Klippel JH, Steinberg AD, Yarboro CH, Balow JE: Controlled trial of pulse methylprednisolone versus two regimens of pulse cyclophosphamide in severe lupus nephritis. Lancet 1992;340:741-745.

4 Flanc RS, Roberts MA, Strippoli GF, Chadban SJ, Kerr PG, Atkins RC: Treatment of diffuse proliferative lupus nephritis: a metaanalysis of randomized controlled trials. Am J Kidney Dis 2004;43:197-208.

5 Houssiau FA, Ginzler EM: Current treatment of lupus nephritis. Lupus 2008;17:426430.

6 Allsion AC, Eugui EM: Purine metabolism and immunosuppressive effects of mycophenolate mofetil (MMF). Clin Transplant 1996; 10:77-84.

\footnotetext{
7 Halloran P, Mathew T, Tomlanovich S, 12 Chan TM, Tse KC, Tang CS, Mok MY, Li FK: Groth C, Hooftman L, Barker C: Mycophe- $\quad$ Long-term study of mycophenolate mofetil nolate mofetil in renal allograft recipients: a pooled efficacy analysis of three randomized, double-blind, clinical studies in prevention of rejection. Transplantation 1997; 63:39-47, (erratum in Transplantation 1997; 63:618).

8 Dimkovic N, Jovanovic D, Kovacevic Z: Mycophenolate mofetil in high-risk patients with primary glomerulonephritis: results of a 1-year prospective study. Nephron Clin Pract 2009;111:c189-c196.

-9 Kitiyakara C, Ophascharoensuk V, Changsirikulchai S, Ingsathit A, Tankee P, Sangpanich A, Sumethkul V: Treatment of lupus nephritis and primary glomerulonephritis with enteric-coated mycophenolate sodium. Clin Nephrol 2008;69:90-101.

10 Paydas S, Kurt C, Taskapan H, Balal M, Sertdemir Y, Pembegul I: The effect of mycophenolate mofetil on primary and secondary treatment of primary glomerulonephritis and lupus nephritis. Int Urol Nephrol 2009; 41:145-152.

$\checkmark 11$ Weixin HU, Zhihong LIU, Huiping $\mathrm{CH}$ Zhen T, Qinwen W, Keqin SH et al: Mycophenolate mofetil vs. cyclophosphamide therapy for patients with diffuse proliferative lupus nephritis. Chin Med J 2002;115: 705-709. as continous induction and maintenance treatment for diffuse proliferative lupus nephritis. J Am Soc Nephrol 2005;16:10761084.

-13 Karim MY, Pisoni CN, Ferro L, Tungekar MF, Abbs IC, D'Cruz DP: Reduction of proteinuria with mycophenolate mofetil in predominantly membranous lupus nephropathy. Rheumatology 2005;44:1317-1321.

14 Hochberg MC: Updating the American College of Rheumatology revised criteria for the classification of systemic lupus erythematosus. Arthritis Rheum 1997;40:1725.

$>15$ Weening JJ, D’Agati VD, Schwartz MM, et al: The classification of glomerulonephritis in systemic lupus erythematous revisited. Kidney Int 2004;65:521-530.

16 Austin HA III, Boumpas DT, Vaughan EM, Balow JE: Predicting renal outcomes in severe lupus nephritis: contribution of clinical and histologic data. Kidney Int 1994;45:544550.

17 Levy AS, Bosch JP, Lewis JB, Greene T, Rogers N, Roth D, Modification of Diet in Renal Disease Study Group: A more accurate method to estimate glomerular filtration rate from serum creatinine: a new prediction equation. Ann Intern Med 1999;130:461467.
} 
18 Cervera R, Font J: Therapeutic perspectives in systemic lupus erythematosus. Curr Rheuma Rev 2005;1:45-47.

$\checkmark 19$ Van Bruggen MC, Walgreen B, Rijke TP, Berden JH: Attenuation of murine lupus nephritis by mycophenolate mofetil. J Am Soc Nephrol 1998;9:1407-1415

-20 McMurray RW, Elbourne KB, Lagoo A, Lal S: Mycophenolate mofetil suppresses autoimmunity and mortality in the female NZB $\times$ NZW F1 mouse model of systemic lupus erythematosus. J Rheumatol 1998;25:23642370.

-21 Gaubitz M, Schorat A, Schotte H, Kern P, Domschke W: Mophenolate mofetil for the treatment of systemic lupus rythematosus: an open pilot trial. Lupus 1999;8:731-736.

-22 Dooley MA, Cosio FG, Nachman PH, et al: Mycophenolate mofetil therapy in lupus nephritis: clinical observations. J Am Soc Nephrol 1999;10:833-839.

23 Ginzler EM, Dooley MA, Aranow C, et al: Mycophenolate mofetil or intravenous cyclophosphamide for lupus nephritis. N Engl J Med 2005;353:2219-2228.

24 Chan TM, Li FK, Tang CSO, Wong RWS, Fang GXJ, Yu L, et al, Hong Kong-Guangzhou Nephrology Study Group: Efficacy of mycophenolate mofetil in patients with diffuse proliferative lupus nephritis. N Engl J Med 2000;343:1156-1162.

-25 Rivera TL, Belmont HM, Malani S, Latorre M, Benton L, Weisstuch J, et al: Current therapies for lupus nephritis in an ethnically heterogeneous cohort. J Rheumatol 2009;36: 298-305.
26 Sahin GM, Sahin S, Kiziltas S, Masatlioglu S, Oguz F, Ergin H: Mycophenolate mofetil versus azathioprine in the maintenance therapy of lupus nephritis. Ren Fail 2008;30:865869.

27 Zhu B, Chen N, Lin Y, Ren H, Zhang W, Wang WM, et al: Mycophenolate mofetil in induction and maintenance therapy of severe lupus nephritis: a meta-analysis of randomized controlled trials. Nephrol Dial Transplant 2007;22:1933-1942.

28 Houssiau FA, Vasconcelos C, D'Cruz D, et al Immunosuppressive therapy in lupus nephritis: the Euro-Lupus Nephritis Trial, a randomized trial of low-dose versus highdose intravenous cyclophosphamide. Arthritis Rheum 2002;46:2121-2131.

29 Contreras G, Pardo V, Leclercq B, et al: Sequential therapies for proliferative lupus nephritis. N Engl J Med 2004;350:971-980.

30 Kapitsinou PP, Boletis JN, Skopouli FN, Boki KA, Moutsopoulos HM: Lupus nephritis: treatment with mycophenolate mofetil. Rheumatology 2004;43:377-380.

31 Ioannidis JP, Boki KA, Katsorida ME, Drosos AA, Skopouli FN, Boletis JN: Moutsopoulos HM: Remission, relapse, and re-remission of proliferative lupus nephritis treated with cyclophosphamide. Kidney Int 2000;57:258-264

>32 Fuming L, Yangke T, Xiaomei P, Lining W, Hanmin W, Zhuxing S, Hongguang Z, Zhao $\mathrm{H}, \mathrm{MMF}$ in Induction Therapy for Active Lupus Nephritis in Mainland China Study Group: A prospective multicentre study of mycophenolate mofetil combined with prednisolone as induction therapy in 213 patients with active lupus nephritis. Lupus 2008;17: 622-629.
33 Mok CC, Lai KN: Mycophenolate mofetil in lupus glomerulonephritis. Am J Kidney Dis 2002;40:447-457.

34 Cross J, Dwomoa A, Andrews P, Burns A, Gordon C, Main J, et al: Mycophenolate mofetil for remission induction in severe lupus nephritis. Nephron Clin Pract 2005; 100:c92-c100.

35 Neumann I, Haidinger M, Jagger H, Grützmacher H, Griesmacher A, Müller MM, Bayer PM, Meisl FT: Pharmacokinetics of mycophenolate mofetil in patients with autoimmune diseases compared to renal transplant recipients. J Am Soc Nephrol 2003;14: 721-727.

36 Zahr N, Amoura Z, Debord J, Hulot JS, Saint-Marcoux F, Marquet P, et al: Pharmacokinetics study of mycophenolate mofetil in patients with lupus erythematosus and design of Bayesian estimator using limited sampling strategies. Clin Pharmacokinet 2008;47:277-284.

37 Kingdon EJ, McLean AG, Psimenou E, Davenport A, Powis SH, Sweny P, et al: The safety and efficacy of MMF in lupus nephritis: a pilot study. Lupus 2001;10:606-611.

>38 Suría S, Checa MD: Mycophenolate mofetil in the treatment of lupus nephritis, in patients with failure, intolerance or relapses after treatment with steroids and cyclophosphamide. Nefrologia. 2007;27:459-465. 